INTERNATIONAL DESIGN CONFERENCE - DESIGN 2018

https://doi.org/10.21278/idc.2018.0406

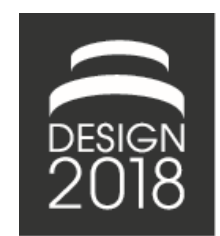

\title{
HOW MUCH KNOWLEDGE MANAGEMENT IS HIDDEN IN DESIGN METHODS?
}

\author{
A. Laukemann, D. Roth and H. Binz
}

\begin{abstract}
The focus of this paper is to provide a beneficial insight into knowledge-management-specific analysis of the design activities involved in design methods. Therefore the objective is to present an approach that outlines how knowledge-management-specific sections of a design method can be identified by means of the modeling language KMDL. This paper is based on the ongoing research results of a product-development-specific knowledge-management approach for SME, and serves as a continuation of research into the influence of information flows and knowledge transformations for design activities.
\end{abstract}

Keywords: knowledge management, design methods, process modelling, process analysis, design process

\section{Introduction}

Knowledge-management research claims to offer a high number of methods for improving the efficiency and effectiveness of problem-solving tasks and routine work (Probst et al., 2012). However, design research also proposes an increasing number of design methods for fulfilling a similar purpose to knowledge-management research. The result is a variety of methods which can no longer be dealt with exclusively. For this reason, Birkhofer (2008) proposed a systematic approach for reducing the variety of design methods using elementary design methods. Unfortunately, the opposite has been observed due to the explosion of design-research subjects and their further diversification, which has resulted in ever more design methods (Birkhofer, 2014).

Nonetheless, all design methods (should) have one thing in common: "a systematic procedure to reach a specific goal" (Pahl et al., 2007). Design research into design processes is beneficial for providing a better understanding of the desired effects of design methods. For decades, design research into design processes has brought forth a proliferation of detailed approaches for describing and analyzing the most knowledge-intensive business processes (Eppler et al., 2008). Generic procedures such as the revised VDI guideline 2221 (VDI 2221, 1993), SPALTEN (Albers et al., 2016) or integrated design engineering (Vajna, 2014) have been successfully transferred from academia to industry. This means that design research provides acknowledged and accepted descriptive models for the product-development process. These range from simple stage-gate guidelines to holistic modeling frameworks and sample design processes with varying levels of abstraction (Wynn et al., 2006). On the other hand, recent design research presents the need to clarify the understanding of design methods to address the slow or incorrect transfer to industrial practice (Gericke et al., 2017). As a current study conducted by Gericke et al. (2017) demonstrates, designers search for design methods based on desired outcomes and not those provided as a generic design-process representation, as is the case in academia.

However, research into design methods also provides approaches for supporting designers by selecting and recommending design methods within the design process. These concepts range from simple design- 
method selection by assignment to design-method attributes (Franke, 2004) and highly complex machine-learning algorithms for recommendation systems (Fuge et al., 2014). Yet even web repositories such as $\mathrm{CiDaD}(\mathrm{CiDaD}$, n.d.) and DesignExchange (DesignExchange, n.d.) or apps like InnoFox (Albers et al., 2015) need to be integrated and developed further within the company-specific design process. Despite extensive design research into design methods, a knowledge-management-specific analysis of the design activities of design methods based on a digital process model has not yet been considered. This will comprise the focal point for this paper. In the next section, the problem statement and objective of this paper will be presented.

\section{Problem statement and objective}

An appropriate design solution can be achieved if the suitable design method is applied at the right time for a defined design problem. Alongside this requisite expertise, methodological competence is also crucial for the correct application of a design method. Many design methods are based on a systematic configuration and a structured approach. Here, the provision of a proper solution is developed gradually. Each design method can be described as a sequence of design activities. In order to successfully process these activities, either personal knowledge or formal information is required. Following the explanation of central terms of a design method, namely "... how information is to be shown, what information is to be used as inputs to the method..." (Gericke et al., 2017), a knowledge-management-specific analysis of design activities within design methods and with an insight into recognized and current knowledgemanagement research enables a detailed view of information flows to be presented, in addition to facilitating knowledge transformations for a certain design activity.

The focus of this paper is to provide a beneficial insight into knowledge-management-specific analysis of the design activities involved in design methods. The main research question of this paper is as follows: "How can knowledge-management-specific sections of design methods be identified and used in order to align suitable knowledge-management methods to design methods with the aim of increasing the support for design processes?"

This research question is based on the ongoing research results of a product-development-specific knowledge-management process for small and medium-sized enterprises (Laukemann et al., 2015), and serves as a continuation of research into the influence of information flows and knowledge transformations for design activities (Laukemann et al., 2017a). In order to give an initial answer to the main research question, an explicit assumption must be expressed in the form of a hypothesis: "By identifying and utilizing knowledge-management-specific sections of design methods, it is possible to align suitable knowledge-management methods to design methods."

As a consequence, the objective of this paper is to present an approach that outlines how knowledgemanagement-specific sections of a design method can be identified by means of the modeling language "Knowledge Modeling and Description Language" (KMDL) developed by Gronau (2009). Furthermore, recommendations for action will be presented in the form of a fact sheet based on the results of the analysis.

\section{State of the art}

In this section, the two main topics related to this paper will be briefly presented. As such, the theoretical basics of knowledge management will be outlined first. In accordance with this, the SECI model of knowledge dimensions proposed by Nonaka and Takeuchi (1995) provides an opportunity to visualize the knowledge transformation in design activities. Subsequently, the Knowledge Modeling and Description Language (KMDL) will be described to aid comprehension of the digital process model of the design activities.

The second main topic constitutes the analyzed design methods and takes the form of a short description.

\subsection{Knowledge management}

Almost all recent results obtained in knowledge-management research can be traced back to the two basic foundations of knowledge management. On the one hand, the so-called knowledge spiral after 
Nonaka and Takeuchi (1995), which explains how knowledge is created, used and distributed in industrial practice. In addition, knowledge-transformation processes are explained in the form of the SECI model (acronym for Socialization, Externalization, Combination, Internalization) and facilitate a differentiation between implicit and explicit knowledge contents. The core activities of knowledge management defined by Probst et al. (2012) are the other essential foundation. These were derived by categorizing repeated activities of knowledge-management-specific problems. The core activities comprising the preservation, identification, acquisition, development, sharing and use of knowledge are often used as a selection criterion for a subsequent method selection (Lehner, 2014). Each knowledgemanagement method addresses at least one core activity and describes a knowledge transformation between implicit and explicit knowledge contents. This systematic connection between core knowledgemanagement activities can be established by differentiating between the knowledge dimensions of the SECI model.

\subsubsection{SECI}

Many well-known authors of knowledge-management approaches rely on the original investigations by Nonaka and Takeuchi (1995), who analyzed knowledge-transformation processes in business environments in detail. The processes of knowledge acquisition within an organization, defined by Nonaka and Takeuchi (1995), are decisive and can be represented by the transformation of tacit and explicit knowledge. This process is described as a knowledge spiral (see Figure 1) and shows how tacit knowledge can be turned into explicit knowledge (and vice versa) with various transformation types. It is possible to define all kinds of knowledge transformation within a business process using just four transformation types (socialization, externalization, combination and internalization).

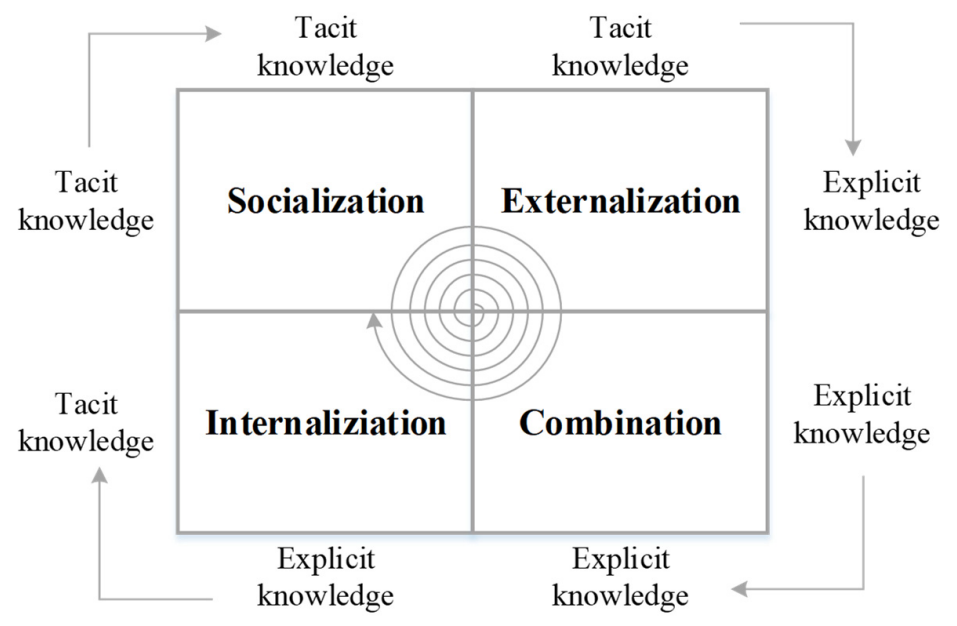

Figure 1. SECI model adapted from Nonaka and Takeuchi (1995)

The transformation type socialization implies that a social interaction involves tacit-to-tacit knowledge transfer. This means that an inexperienced person acquires mental models and technical skills by observing and imitating experienced persons. An interaction involving a conversion from tacit to explicit knowledge is described as an externalization. Therefore, personal knowledge must be converted as analogies, metaphors, models and hypotheses into explicit knowledge, which can be shared and preserved. Combination defines an interaction as an explicit-to-explicit knowledge transfer. This transformation type is not as knowledge-intensive as the others. Existing explicit knowledge in the form of information can connect, classify and generate new explicit knowledge in the form of information. An interaction involving a conversion from explicit to implicit knowledge is described by the transformation type internalization. This kind of transformation is often described with the sentence "learning by doing". In fact, this process requires specific skills on the part of the person who is newly supplementing their own personal knowledge (Nonaka and Takeuchi, 1995). 


\subsubsection{Core knowledge-management activities}

Probst et al. (2012) identified problems with regard to knowledge management in companies by means of some practice-oriented research activities. These were subsequently grouped into problem categories. The categorization of repeated activities led to defined core activities of knowledge management (see Figure 2). Probst et al. (2012) described different knowledge-management methods for each core activity.

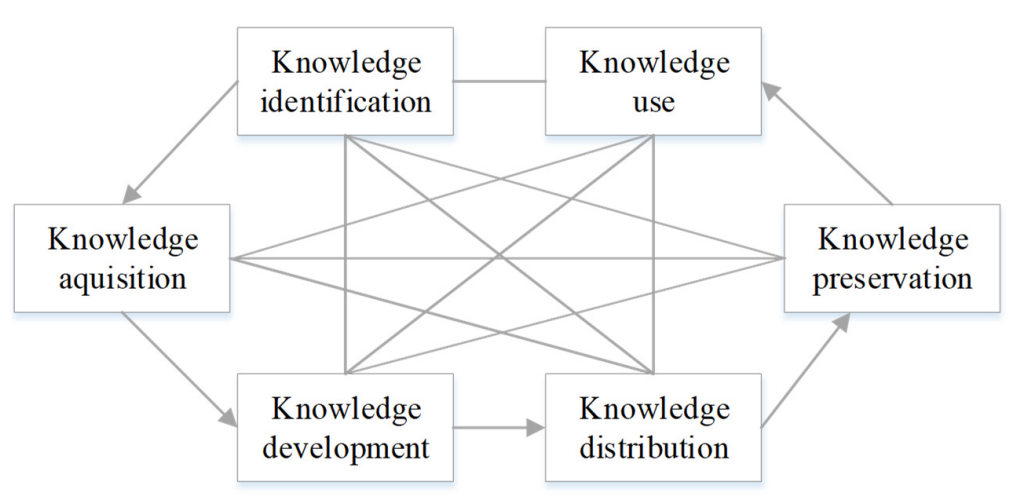

Figure 2. Core knowledge-management activities adapted from Probst et al. (2012)

These core activities are used as guidelines or as categorization schemes in many knowledgemanagement approaches. This can be helpful if numerous knowledge-management methods have to be structured and organized in order to support the user by selecting suitable methods. For that reason, Binz et al. (2016) provide a matrix in which several knowledge-management methods are mapped to the core knowledge-management activities. Detailed and holistic descriptions of the different core knowledge-management activities are not explained here. For further information, refer to Probst et al. (2012). A brief description is provided below to facilitate sufficient comprehension of the core knowledge-management activities and their connections to the types of knowledge transformation. Most of the issues and challenges related to knowledge management within an industrial environment can be traced back to insufficient identification of relevant knowledge. If a lack of necessary knowledge is identified, the company can acquire (external) knowledge, such as from a knowledge market place (North, 2016). On this knowledge market place, intangible (consultants) and material knowledge products (software, books, etc.) can be purchased. However, if non-existent knowledge is considered to be crucial expertise for the company, the internal development of this specific knowledge content should be generated through workshops, training courses, etc. Similar to the core activity of knowledge identification, the distribution of knowledge within the company is an essential success factor (Probst et al., 2012). One prerequisite for knowledge distribution is a systematic preservation of organizational knowledge. The use of knowledge represents the minimum objective of each knowledge-management system.

\subsubsection{KMDL - a modeling language for capturing knowledge-intensive business processes}

The semi-formal "Knowledge Modeling and Description Language" (KMDL) developed by Gronau (2009) enables digital mapping of knowledge-intensive business processes. This modeling language is based on the unified modeling language (UML), which enables widespread use for different software systems. The main feature of this modeling language is the consideration of the different types of knowledge transformation (see Nonaka and Takeuchi (1995)) and the resulting traceability of how personal knowledge can be organized. The activity view modeled in detail represents all activities and necessary information, in addition to personal knowledge. A detailed description of different objects, notations and modeling processes of KMDL is not described in detail here. For further information, refer to Gronau (2009). Figure 3 shows all relevant objects of the process and activity view. 


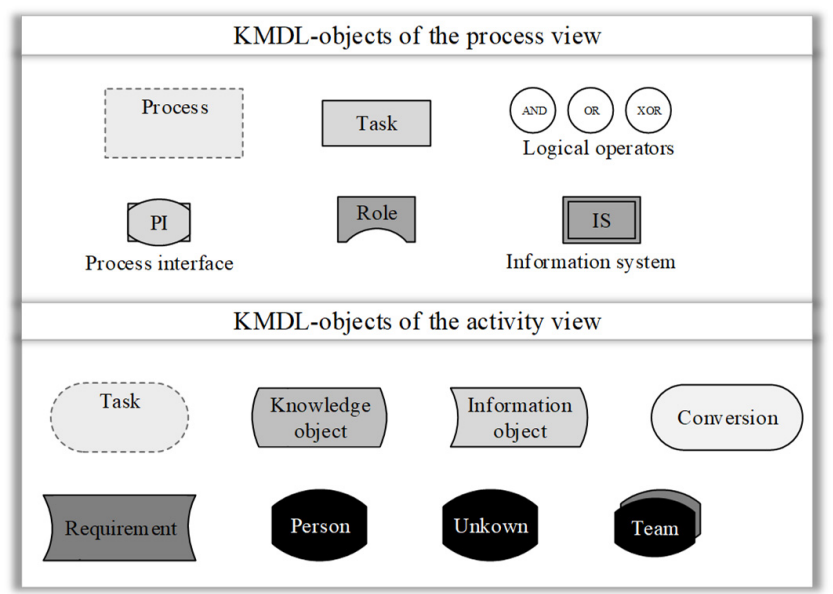

Figure 3. KMDL objects of process and activity view, adapted from Gronau (2009)

In KMDL, the knowledge flow is expressed through modeled conversions between input and output objects, whereby the conversion type describes the number of input and output objects. They are subdivided into three types (atomic, complex and abstract). The four modeled dimensions of knowledge transformation (presented in Figure 4) are one example of atomic conversions.

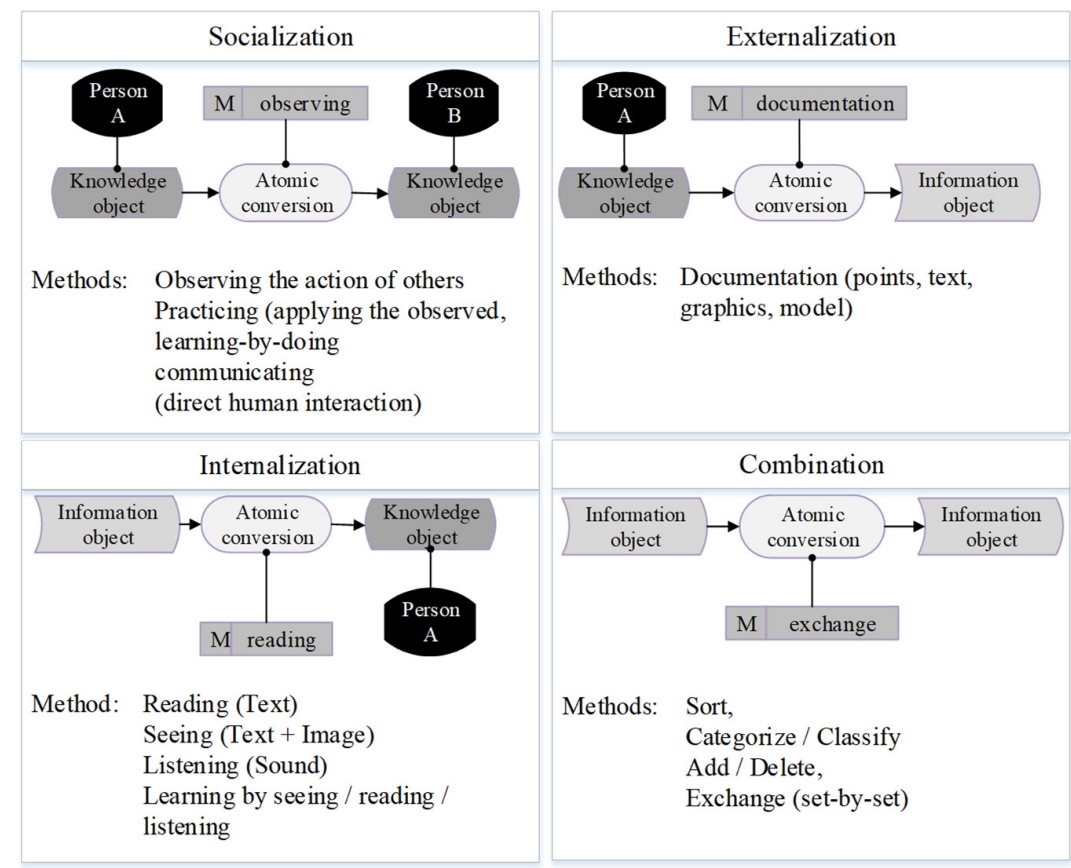

Figure 4. SECI model represented by KMDL atomic conversion (Gronau, 2009)

\subsection{Design methods}

In contrast to generally applicable knowledge-management methods, product-development methods can be assigned and applied in a process-oriented manner. Guideline VDI 2221 provides modular and iterative process steps for a generic design process which produces different work results (VDI 2221, 1993). These results can be supported methodologically. Special features and the systematic handling of product-development methods are not given here as they are already described in detail in the relevant literature (see Feldhusen and Grote (2013)). However, to establish a basis for further analysis, several design methods have been modeled using the modeling language described in Section 3.1.3. The analyzed and modeled product-development methods are listed below (see Table 1). 
Table 1. Compilation of analyzed design methods

\begin{tabular}{|c|c|c|}
\hline ABC analysis & Kano model & Requirements list \\
\hline Application of a design catalog & Mind Map & Selection list \\
\hline Benefit analysis & Paired comparison & SWOT analysis \\
\hline Brainstorming & Qualitative fault tree analysis & Technical and economic evaluation \\
\hline Failure Mode and Effects Analysis & Quality Function Deployment & Walt Disney method \\
\hline
\end{tabular}

The following section contains only a brief description of one of the analyzed and modeled design methods (this method serves as a continuous example to explain later the systematic approach). For a detailed and comprehensive understanding of each design method, refer to Feldhusen and Grote (2013). The requirements list represents a methodological tool which allows a documentation of customers' requirements. Requirements are accordingly collected, structured and entered into a predefined form together with the customer. It is important to ensure that the list of requirements is always up to date.

\subsection{Conclusion regarding the state of the art}

With the findings from knowledge-management research and a precise digital KMDL process model of design methods, it is possible to derive a concept for a systematic approach for identifying knowledgemanagement-specific sections within design methods. The existing design-method fact sheets include numerous general attributes and characteristics such as the necessary number of employees, duration of applying the method, resources, goals, working steps, and so forth. These fact sheets can be supplemented by knowledge-management-specific selection criteria which are more closely related to the problem-oriented solution-finding processes desired by design engineers. Furthermore, the underlying digital process model of each analyzed design method will increase process transparency, which will in turn address the lack of clarity in design methods (Gericke et al., 2017). In this way, the design methods will be enriched with suitable metadata. These metadata can be used directly by design engineers or serve as a backbone for a digital platform that supplies the requesting design engineer with target-oriented information in the form of a customized graphical user interface (GUI).

\section{Concept for a systematic approach for identifying knowledge-management- specific sections of design methods}

As previously stated, the main advantage of KMDL is the consideration and implementation of the personal knowledge transformations within a (design) activity. Widely used modeling languages such as SysML (Eigner et al., 2017), BPMN (Allweyer, 2009) or EPC (Staud, 2006) have their own inherent advantages, although all of them lack traceability of personal knowledge content within the modeled processes. This thesis, which is listed in literature (Gronau, 2009), was successfully confirmed in the course of an industrial project. In this case, our industrial partner modeled all business processes using the BPMN modeling language. The results are numerous so-called "swim lanes" in different "pools" provided by means of a digital platform. Multiple conclusions could be gained by conducting an interview. On the one hand, the employees involved consider the processual representation of process steps with their interfaces to different business units, as well as the attachment of documents as data objects (artefact), to be beneficial. On the other hand, however, a detailed analysis of the swim lanes reveals significant weaknesses in terms of the granularity of the BPMN process model. For instance, the model contains a process step called "perform construction" with a multitude of attached documents, checklists and templates. The fact is that each design engineer involved describes this process step in a different way. In this particular project, the BPMN process model served as a blueprint for KMDL modeling. The different views of KMDL enabled a more detailed digital process model to be established without disregarding the advantages of the guided, superordinate process steps. As a preliminary result, KMDL process models can apparently provide the requisite granularity for design activities. However, this is not enough to support the identification and use of knowledge-management-specific sections of a design method. The KMDL notation must therefore be supplemented by the core knowledgemanagement activities. As mentioned in Section 3, the KMDL notation already takes account of the 
SECI model (see Figure 4). The knowledge transformation (especially the differentiation between information [explicit knowledge] and knowledge [tacit knowledge]) helps to identify knowledgemanagement-specific sections within a given design activity. A preliminary procedure (see Figure 5) divided into three steps was derived from the general process for modeling with KMDL (Gronau, 2009).

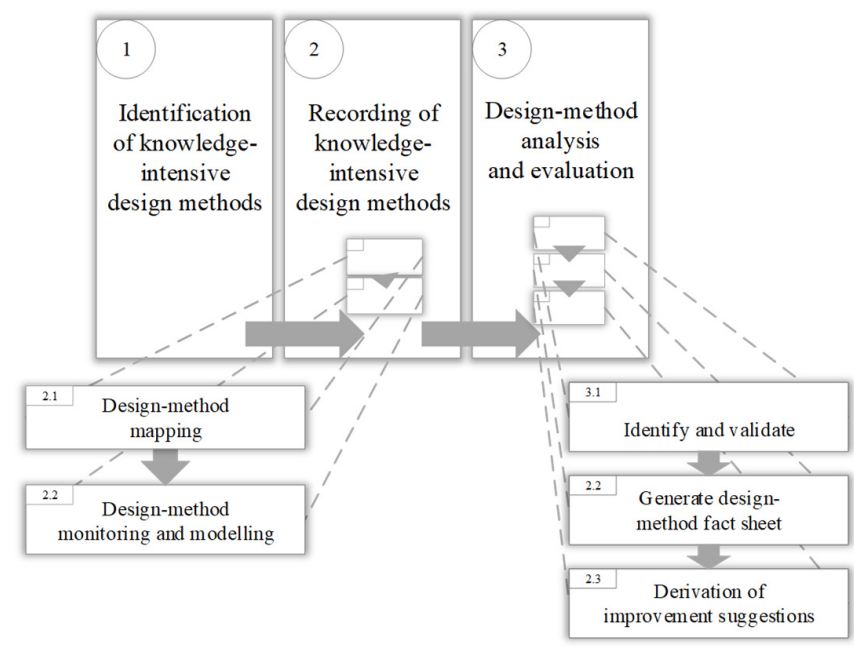

Figure 5. Procedure for identifying knowledge-management-specific sections within design methods, adapted from (Gronau, 2009)

The first step involves the identification of relevant design methods. In this case, a literature review was conducted, after which frequently quoted design methods and experience from industrial projects (2 large enterprises and 2 medium-sized enterprises) were considered (see Table 1). The second step is subdivided into two activities. Initially, the design method to be modeled needs to be mapped. The usually existing fact sheet, which provides rough information about superordinate process steps, can therefore be used. The modeling of the design method subsequently starts and the notation of KMDL and the principles of proper modeling are considered (Becker et al., 2012). As a result, the KMDL process model (see Figure 6) of the design method forms the basis for the following analysis (step 3). The process view of the design method "requirements list" with the highlighted activity view of the process step "arrange requirements" is shown as an example in Figure 6.

Process view of the design method requirements list

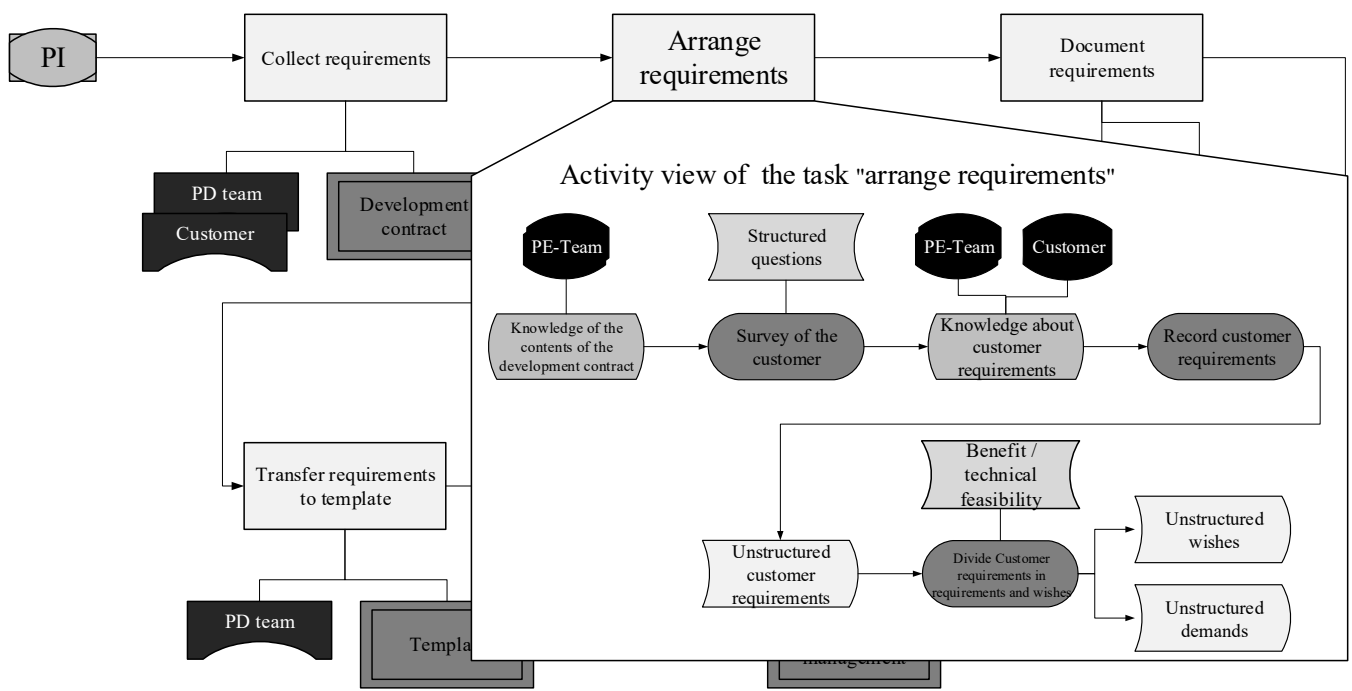

Figure 6. KMDL process model for the design-method requirements list 
The activity views for each task in the process view are particularly important for analysis because they contain the various modeled knowledge transformations. As mentioned before, the activity view provides the visualization of the knowledge transformations and information flows alike. In order to identify knowledge-management-specific sections within a design activity, the link between knowledge transformation (SECI model) and core knowledge-management activities must be established. Each time personal knowledge serves as an input object for a knowledge transformation (socialization or externalization), the core activity "knowledge use" can be linked to this activity. If knowledge is transformed into information (externalization), this activity directly addresses the core knowledgemanagement activity "knowledge distribution". In case of a lack of organizational knowledge, the company might obtain knowledge from a consultancy. This kind of knowledge transformation would be linked to the core activity "knowledge acquisition" (see Figure 7).

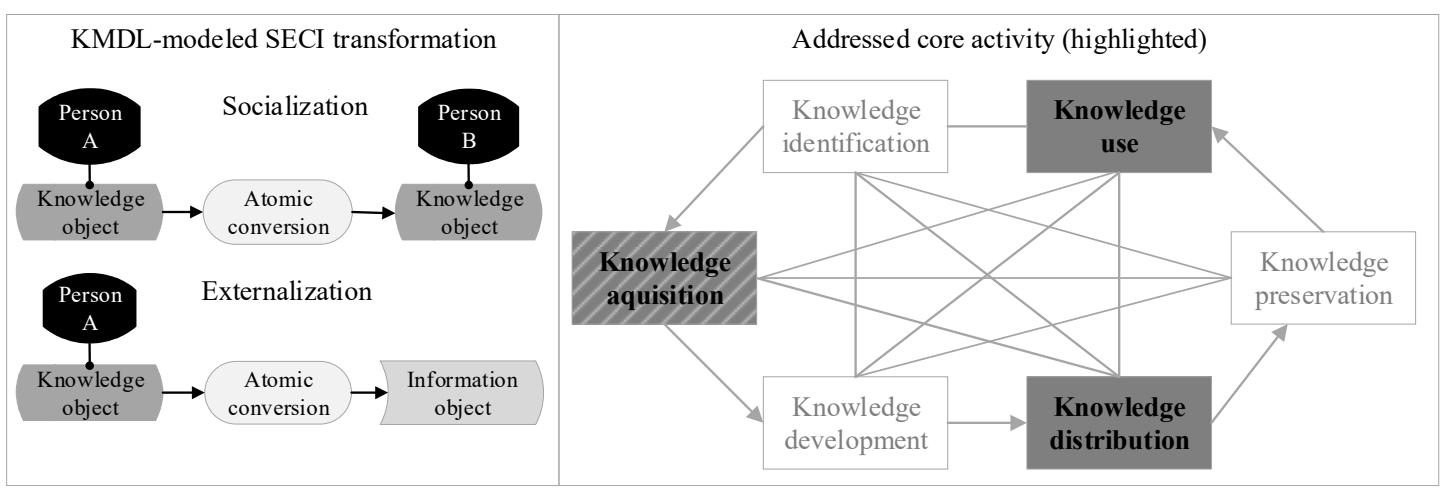

Figure 7. Link between SECI model (socialization, externalization) and core knowledge-management activities (knowledge use, acquisition, distribution)

The knowledge transformation type "externalization" itself represents the core knowledge-management activity "knowledge preservation". In that regard, a personal knowledge object is transformed through documentation into an explicit knowledge object (i.e. information object). Although some context and details are missing from this transformation, the huge advantage is that every employee now has access to this information object (see Figure 8). Consequently, each time there is an externalization within a design activity, the application of a knowledge-management method which addresses the "knowledge preservation" would be useful in order to support the follow-up projects.

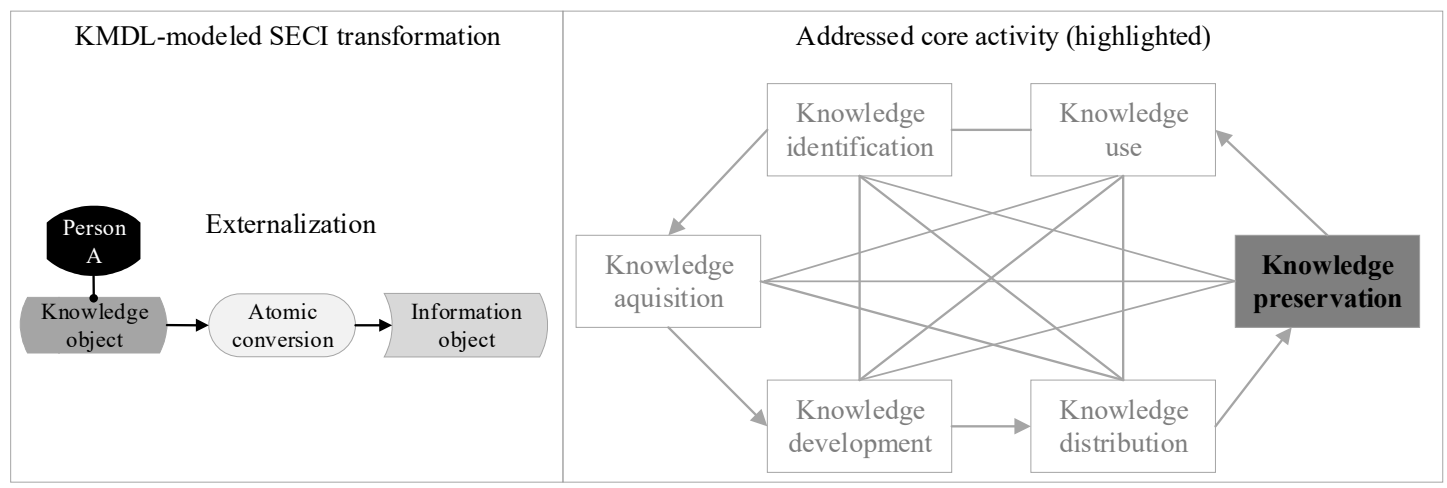

Figure 8. Link between SECI model (externalization) and core knowledgemanagement activity (knowledge preservation)

In contrast to the core activity "knowledge acquisition", the core activity "knowledge development" deals with internal knowledge generation. In many cases, it is necessary for crucial expertise to be developed by companies themselves instead of contacting external consultants. In order to successfully develop relevant knowledge, the responsible employee needs special competencies to assimilate new knowledge on the basis of existing information (see Figure 9). 


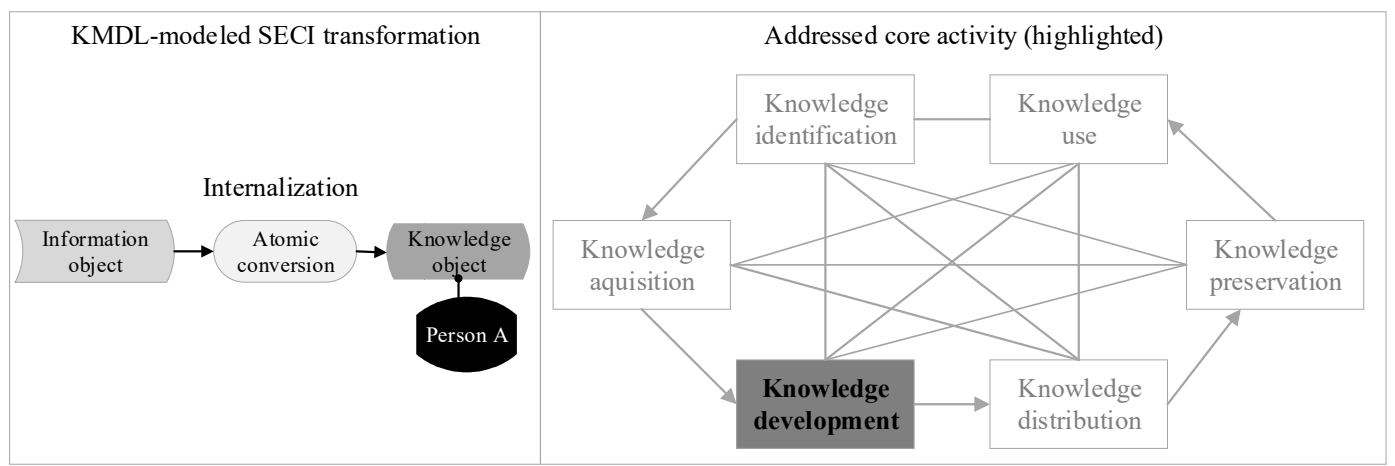

Figure 9. Link between SECI model (internalization) and core knowledgemanagement activity (knowledge development)

As a general rule, the links and relationships between the knowledge transformation and the core knowledge-management activity concerned are based on a simple input-output analysis. The knowledge transformations "socialization" and "externalization" have a knowledge object as an input object. Therefore, it is obvious that a design activity modeled as socialization or externalization can be mapped with the core knowledge-management activities "knowledge use" and "knowledge distribution", in addition to "knowledge acquisition" (if it is an external knowledge carrier). The externalization of personal knowledge in the form of non-personal information can be assigned to "knowledge preservation". Personal knowledge can be developed when sufficient information is available and the person involved is able to process that information. Obviously, this can also cause some overlapping of knowledge transformations and their associated core knowledge-management activities. Detailed and knowledge-managementspecific investigations can be conducted according to this systematic procedure for analyzing each design activity of the provided design methods. The prepared results are visualized with different diagrams and supplement the existing fact sheet for the respective design method (see Figure 10).

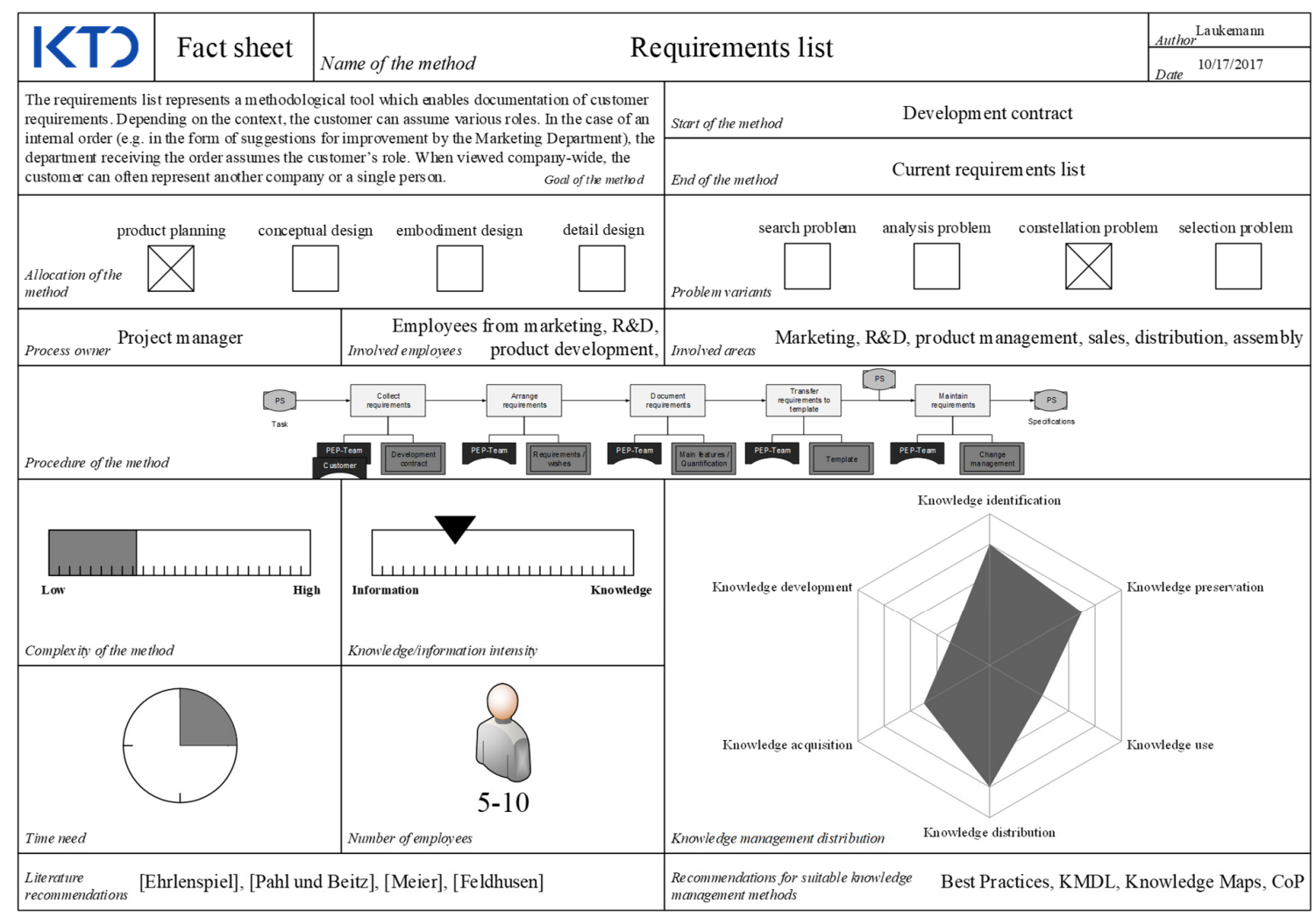

Figure 10. Fact sheet for the design method "requirements list" 
Besides the general information concerning the design method to be analyzed, the knowledgemanagement-specific diagrams and specifications on the lower half of the fact sheet are also important. The complexity of the method is presented by a status bar and depends on the quantity of modeled objects and connection points. Another noteworthy diagram is the slide bar, which indicates whether the design method is more information- or knowledge-intensive.

The slide bar shows at a glance, whether the analyzed process step contains more information objects or more knowledge objects. With this understanding a solid basis is established for better decisions to be taken.

The most significant diagram on the fact sheet takes the form of the radar chart. This chart provides the distribution of all knowledge transformations and their links to the core knowledge-management activities, and allows some recommendations for support to be derived by means of suitable knowledgemanagement methods. In this case, the design method requirements list consists of many process steps, which support several knowledge-management core activities like "knowledge distribution" or "knowledge identification". This particular insight serves as basis of an appropriate advice on expedient knowledge-management methods.

Within the digital process model, the recommendation is described by the KMDL object PI (process interface) and interconnects the process model with a suitable knowledge-management method (see Figure 11).

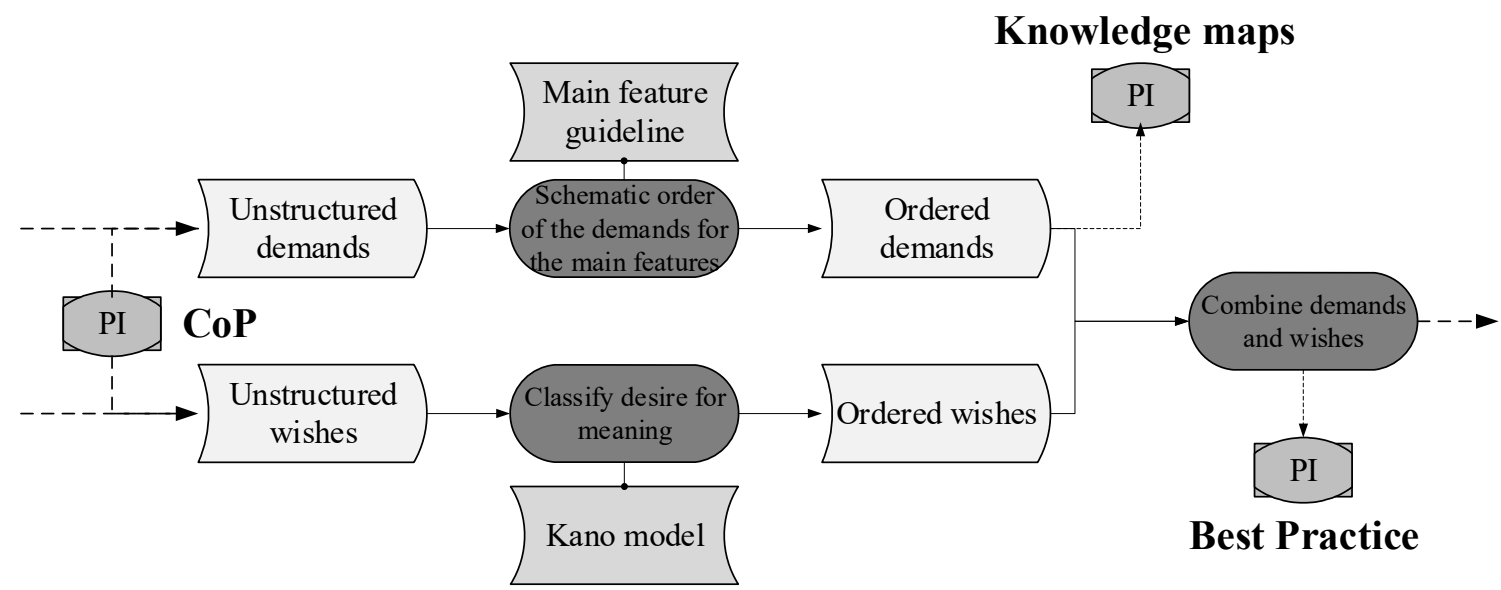

Figure 11. Possible interactions between a design activity and a suitable knowledgemanagement method

Similar to the system of links between knowledge transformations and core knowledge-management activities, the selection of a suitable knowledge-management method is based on an input-output analysis. For example, the knowledge conversion "combine demands and wishes", with its two input objects "ordered demands" and "ordered wishes", can be supported by the knowledge-management method "best practice". Therefore, the two information objects serve as input objects for selecting a best practice (see Figure 11).

In addition, the before mentioned input-output analysis to recommend appropriate knowledgemanagement methods is associated with a solution catalog, which provides already KMDL-modelled knowledge-management methods and their fact sheets for an easy integration (Laukemann et al., 2017b). The access to the solution catalog through the classifying criteria is based on the results of the inputoutput analysis previously conducted.

\section{Discussion of the results}

Until now, the research question addressing the way in which knowledge-management-specific sections of design methods can be identified and used to align suitable knowledge-management methods with design methods in order to increase the support for design processes could only be answered in part. The presented approach is yet to be finally evaluated. 
An initial evaluation of the digital process models of the modeled design methods has taken place and concluded that it is possible to identify knowledge-management-specific sections using a KMDL process model and the system in the presented approach.

A detailed investigation into the interconnection between individual design activities and suitable knowledge-management methods with an input-output analysis could only be established away from practical applications. For this reason, a comprehensive evaluation in industry is still pending.

\section{Conclusion and outlook}

Based on the described problem statement and the misunderstanding among design methods in general, not to mention the proper application in industrial environments, the presented approach was developed in order to support the identification of knowledge-management-specific sections of design methods.

The achieved goal was to use such knowledge-management-specific sections in order to bridge the gap between design methods and knowledge-management methods. The presented systematic approach promotes the understanding of how suitable knowledge-management methods are able to support design methods. This approach takes place within a holistic framework in order to establish knowledgemanagement-specific product development and directly supports the task "target-oriented support for the product-development process" (Laukemann et al., 2015).

At present, a comprehensive analysis of how this systematic approach influences the support of the design process is still lacking. However, the support potential offered by linking knowledgemanagement methods to design methods could still be identified.

\section{References}

Albers, A., Reiß, N., Bursac, N. and Breitschuh, J. (2016), “15 Years of SPALTEN Problem Solving Methodology in Product Development”, Proceedings of NordDesign 2016, Trondheim, Norway, August 10-12, 2016, The Design Society, Bristol, United Kingdom, pp. 411-420.

Albers, A., Reiss, N., Bursac, N., Walter, B. And Gladysz, B. (2015), "InnoFox - Situationsspezifische Methodenempfehlung im Produktentstehungsprozess", In: Binz, H., Bertsche, B., Bauer, W. and Roth, D. (Eds.), Stuttgarter Symposium für Produktentwicklung 2015, Fraunhofer Verl., Stuttgart.

Allweyer, T. (2009), BPMN 2.0 Business Process Model and Notation, Books on Demand, Norderstedt, Germany.

Becker, J., Probandt, W. and Vering, O. (2012), Grundsätze ordnungsmäßiger Modellierung: Konzeption und Praxisbeispiel für ein effizientes Prozessmanagement, BPM kompetent, Springer Berlin Heidelberg, Berlin, Heidelberg. https://doi.org/10.1007/978-3-642-30412-5

Binz, H., Roth, D. and Laukemann, A. (2016), "Wissensmanagement”, In: Lindemann, U. (Ed.), Handbuch Produktentwicklung, Carl Hanser, München, pp. 247-271.

Birkhofer, H. (2008), "Tidy Up Design Methods - An Approach Using Elementary Design Methods", Proceedings of the DESIGN 2008 / $10^{\text {th }}$ International Design Conference, Dubrovnik, Croatia, May 19-21, 2008, The Design Society, Zagreb, pp. 1-8.

Birkhofer, H. (2014), “Are we aware what we are doing in Design Research?”, Proceedings of the ICDES 2014 /

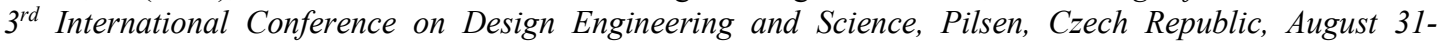
September 3, 2014, pp. 1-10.

CiDaD (n.d.), CiDaD - Competence in Design and Development. [online] Lehrstuhl für Produktentwicklung, Technische Universität München. Available at: http://www.cidad.de/portal/ (accessed 10.2017).

DesignExchange (n.d.), Collaborative Research. TheDesingExchange, Interactive Portal for the Desing Community of Practice. [online] UC Berkley and MIT. Available at: https://www.thedesignexchange.org/ (accessed 10/2017).

Eigner, M., Koch, W. and Muggeo, C. (2017), Modellbasierter Entwicklungsprozess cybertronischer Systeme: Der PLM-unterstützte Referenzentwicklungsprozess für Produkte und Produktionssysteme, Springer Berlin Heidelberg, Berlin. https://doi.org/10.1007/978-3-662-55124-0

Eppler, M.J., Seifried, P. and Röpnack, A. (2008), "Improving knowledge intensive processes through an enterprise knowledge medium", In: Meckel M. and Schmid, B. (Eds.), Kommunikationsmanagement im Wandel, Springer Gabler, Wiesbaden, pp. 371-389. https://doi.org/10.1007/978-3-8349-9772-2_19

Feldhusen, J. and Grote, K.-H. (2013), Pahl/Beitz Konstruktionslehre: Methoden und Anwendung erfolgreicher Produktentwicklung, Springer Vieweg, Berlin, Heidelberg. https://doi.org/10.1007/978-3-642-29569-0

Franke H.-J., D.M. (2004), "Selecting And Combining Methods For Complex Problem Solving Within The Design Process", Proceedings of the DESIGN 2004 / $8^{\text {th }}$ International Design Conference, Dubrovnik, Croatia, The Design Society, Glasgow, pp. 213-218. 
Fuge, M., Peters, B. and Agogino, A. (2014), "Machine Learning Algorithms for Recommending Design Methods", Journal of Mechanical Design, Vol. 136 No. 10, pp. 101103. https://doi.org/10.1115/1.4028102

Gericke, K., Eckert, C. and Stacey, M. (2017), “What do we need to say about a design method?", Proceedings of the ICED'17 / $21^{\text {st }}$ International Conference on Engineering Design, Vol 7: Design Theory and Research Methodology, Vancouver, Canada, August 21-25, 2017, The Design Society, pp. 101-110.

Gronau, N. (2009), Wissen prozessorientiert managen: Methode und Werkzeuge für die Nutzung des Wettbewerbsfaktors Wissen in Unternehmen, Oldenbourg, München.

Laukemann, A., Binz, H. and Roth, D. (2015), "Konzept eines produktentwicklungsspezifischen Wissensmanagementverfahrens für kleine und mittlere Unternehmen”, In: Binz, H., Bertsche, B., Bauer, W. and Roth, D. (Eds.), Stuttgarter Symposium für Produktentwicklung 2015, Fraunhofer Verl., Stuttgart, Stuttgart.

Laukemann, A., Binz, H. and Roth, D. (2017a), "Concept for a simulation model to analyze knowledge conversions within the product development process", Proceedings of the ICED'17 / $21^{\text {st }}$ International Conference on Engineering Design, Vol 7: Design Theory and Research Methodology, Vancouver, Canada, August 21-25, 2017, The Design Society, pp. 21-30.

Laukemann, A., Binz, H. and Roth, D. (2017b), "Katalog von Wissensmanagementlösungen für den Produktentwicklungsprozess", In: Binz, H., Bertsche, B., Bauer, W. and Roth, D. (Eds.), Stuttgarter Symposium für Produktentwicklung 2017, Fraunhofer Verl., Stuttgart, Stuttgart.

Lehner, F. (2014), Wissensmanagement: Grundlagen, Methoden und technische Unterstützung, 5th ed., Carl Hanser, München.

Nonaka, I. and Takeuchi, H. (1995), The knowledge-creating company: How Japanese companies create the dynamics of innovation, Oxford University Press, New York.

North, K. (2016), Wissensorientierte Unternehmensführung: Wissensmanagement gestalten, 6th ed., Springer Gabler, Wiesbaden. https://doi.org/10.1007/978-3-658-11643-9

Pahl, G., Beitz, W., Feldhusen, J. and Blessing, L. (2007), Engineering design: A systematic approach, 3rd ed., Springer, London. https://oi.org/10.1007/978-1-84628-319-2

Probst, G., Raub, S. and Romhardt, K. (2012), Wissen managen: Wie Unternehmen ihre wertvollste Ressource optimal nutzen, 7th ed., Gabler, Wiesbaden. https://doi.org/10.1007/978-3-8349-4563-1

Staud, J.L. (2006), Geschäftsprozessanalyse: Ereignisgesteuerte Prozessketten und objektorientierte Geschäftsprozessmodellierung für betriebswirtschaftliche Standardsoftware, 3rd ed., Springer Berlin Heidelberg, Germany. https://doi.org/10.1007/3-540-37976-2

Vajna, S. (2014), Integrated Design Engineering: Ein interdisziplinäres Modell für die ganzheitliche Produktentwicklung, Springer Vieweg, Dordrecht. https://doi.org/10.1007/978-3-642-41104-5

VDI 2221 (1993), Methodik zum Entwickeln und Konstruieren technischer Systeme und Produkte, Vol. 03.100.40 No. 2221, Beuth-Verlag, Berlin.

Wynn, D.C., Eckert, C.M. and Clarkson, P.J. (2006), “Applied Signposting: A Modeling Framework to Support Design Process Improvement”, Proceedings of ASME 2006 International Design Engineering Technical Conferences and Computers and Information in Engineering Conference, Philadelphia, Pennsylvania, USA, September 10-13, 2006, ASME, New York, pp. 553-562. https://doi.org/doi:10.1115/DETC2006-99402

Alexander Laukemann, Dipl.-Ing.

University of Stuttgart, Institute for engineering design and industrial design

Pfaffenwaldring 9, 70569 Stuttgart, Germany

Email: alexander.laukemann@iktd.uni-stuttgart.de 